\title{
La acción masiva. Escala y repertorios en el estallido social chileno
}

\author{
The massive action. \\ Scale and repertoires in the Chilean social protest
}

JORGE Vergara VIDAL ${ }^{1}$

Cómo citar este artículo: Vergara Vidal, J. (2021). La acción masiva. Escala y repertorios en el estallido social chileno. Revista de Ciencias Sociales Ambos Mundos, (2), 55-67. https://doi.org/10.14198/ambos.20982

\begin{abstract}
Resumen
La reflexión sobre los efectos sociales de los fenómenos masivos es temprana dentro de la sociología. Los trabajos de Le Blanc, de Tarde y de Park, entre otros, ayudaron a dibujar la figura de un tipo particular de actor que, sin embargo, no llegó a consolidarse como un objeto de observación y análisis dentro de la disciplina, dado el rápido avance de los procesos de racionalización organizacional y la consolidación de unidades de análisis que los explicaban mejor, como son los actores vinculados a la acción individual y a la acción asociada o colectiva. El presente texto aborda el análisis de los actores masivos en el caso chileno, en particular en los hechos detonados por los sucesos de protestas comenzados en octubre de 2019. Se utiliza para ello un enfoque hermenéutico que ayudar a identificar y situar prácticas y efectos masivos asociables a este tipo de actor, y sugieren considerarlo para el análisis de la acción socio material en las ciudades.
\end{abstract}

Palabras claves: Masas; protestas; acción; repertorios; ciudades.

\section{Abstract}

In sociology, reflection on the social effects of mass phenomena is early. The works of Le Blanc, Tarde and Park, among others, helped to sketch the figure of a particular type of actor which, however, did not become consolidated as an object of observation and analysis within the discipline, given the rapid advance of the processes of organizational rationalization and the consolidation of units of analysis that explained them better, such as actors linked to individual action and associated or collective action. The present text addresses the analysis of mass actors in the Chilean case, particularly in the events triggered by the events of protests that began in October 2019, using a hermeneutic approach that helps to identify and situate practices and mass effects associated with this type of actor, and suggests considering it for the analysis of sociomaterial action in cities.

Keywords: Masses; mass protests; action; repertoires; cities.

1. Jorge Vergara Vidal, Universidad de Valparaíso, Chile. jorge.vergaravi@uv.cl https://orcid.org/0000-0002-7712-4090 


\section{LOS ACTORES MASIVOS}

Las ciudades se organizan materialmente en función de actores y prácticas a la par que brindan un sentido relacional en el espacio (Delfante, 2005), así funciona lo que el sociólogo Maurice Halbwachs (2008) denominaba morfología de las ciudades: no sólo como una forma articulada en torno a una o más funciones, sino como un conjunto de arreglos socio espaciales que emergen de la sensibilidad de los actores a las controversias propias de su interacción. De manera que la reorganización del París decimonónico no solo es efecto de su crecimiento poblacional y de las necesidades de orden de sus individuos, sino también de las epistemologías de sus actores colectivos, lo cual no se limita a sus grupos organizados en torno a intereses y propósitos, sino también a las agregaciones donde no es posible distinguir estos elementos.

Es este segundo tipo de actores el que ocupa la atención de este trabajo, no solo por su protagonismo en los eventos de protesta masiva comenzados el 18 de octubre de 2019, sino porque movilizan una semiótica material que es necesaria de tener en cuenta en el ordenamiento urbano de las ciudades chilenas, pues ha estado consolidándose hace más tiempo del que es posible suponer y, probablemente, la fase neoliberal de nuestro periférico capitalismo sólo haya ayudado a desarrollar.

Sucesos como los detonados en octubre de 2019 adquieren una escala que les facilita tener efectos en las formas urbanas (Halbwachs, 2008; Harvey, 2006), por ello es de interés inquirir sobre el tipo de actor capaz de realizarlos. Cuando el análisis sociológico ha tomado en cuenta a este tipo actores, de escala masiva, ha procurado distinguir si se trata de entidades colectivas capaces de expresar identidad a través de una unidad de propósito, como en el caso de Leviathan de Hobbes (2017), o agregaciones de entidades unificadas por la contingencia, como ocurre con Behemoth, del mismo autor (Hobbes, 1992); aunque también es posible distinguir la acción de otro tipo de entidades, ya no humanas, como los Tirakuna o Seres Tierra descritos por Marisol de la Cadena (2015). En todos los casos se está frente a actores (o actantes) de una escala que deja huellas enormes (Tilly, 1991).

Lo masivo constituía una novedad para el análisis social en 1904, según señala un joven Robert Ezra Park, lo que determinaba que su trabajo se desarrollara en torno a nociones indeterminadas: "donde no existe una tradición científica previa, faltan necesariamente también las determinaciones exactas de las palabras que requieren sus objetos", sostenía (1996, p. 362). El mismo Park (1996), siguiendo la estela de los trabajos anteriores de Gustave Le Blon (2000) y de Gabriel Tarde (2011), procuró establecer una mejor imagen identificándolo como un tipo de individualidad, no como una mera agregación de individuos, dado que expresaba propiedades comunes a quienes la componen. Esta función de lo común en la constitución de los actores masivos es considerada también por Antonio Negri $(2015,2020)$ en su noción de multitud, y por otros autores que proponen lo masivo como un tipo de colectivo social (Borch, 2012; Sundararajan, 2019) que también podría ser entendido un macro-actor (Callon y Latour, 1981).

Preguntarse por este tipo de actores, como sostiene Boltanski, adquiere mayor importancia cuando se busca proponer "una explicación para dar cuenta de un estado de la sociedad, identificado por contraste con el Estado que prevalece en otras sociedades comparables, o de un cambio social o, de manera aún más apremiante, de un acontecimiento" (2016, p. 268), como sucede con el estallido social. Dado que las explicaciones sociológicas captan a estas entidades masivas en el curso de interacciones, se hacen necesarias nociones de mayor escala y estabilidad que puedan fijar analíticamente dicha información, de manera que se establece que, por lo menos, sus interacciones ocurren dentro de situaciones (Boltanski, 2016; Thomas, 1923), las cuales pueden ser diferenciadas según su estabilidad y ser útiles para explicar los cambios de estado o acontecimientos.

Boltanski sostiene que la amplitud y consecuencias de los acontecimientos "dependen de la posición que ocupan las personas presentes en la situación observada, en el seno de conjuntos más grandes y, particularmente, de las repercusiones que sus acciones y decisiones tienen sobre otros actores, dicho de otro modo, de su poder" (2016, p. 270). Tal como ocurre en Hobbes, son actores de escala individual los que dan cuenta de la acción de las entidades masivas, y es la heterogeneidad de sus expresiones sobre aquello (narrativas) lo que ayuda a configurar explicaciones e identidades a utilizar en interacciones futuras con ellas.

La posición física, cultural o ideológica desde las que se producen las narrativas las determina. Pero a la vez nunca se cuenta con una sola observación. Narrativas cambiantes, contradictorias o poco homogéneas no conllevan que los hechos sean relativos, sino que los arreglos sociales para trabajar con ellos no están totalmente asentados. 
Ello cabe sobre todo para definir a los actores de gran escala mencionados.

El texto que sigue reflexiona sobre las narrativas elaboradas para dar cuenta de la acción, identidad y efectos urbanos de los actores masivos visibles a partir los eventos de octubre de 2019. Se utiliza un enfoque hermenéutico, adecuado a las ciencias sociales (Bauman, 2007), que es aplicado a piezas de prensa, literatura y a entrevistas realizadas por el autor en el marco de otras investigaciones, en particular al arquitecto Juan Honold Dunner durante julio de 2018 a enero de 2019 con financiamiento del Fondecyt $N^{\circ} 3170016$.

La conclusión de este ejercicio es acotada, y solo espera ofrecer una perspectiva útil para verificar la acción de entidades masivas, no individuales, aunque tampoco organizadas por intereses comunes, como ocurre con las organizaciones y otros tipos de actores colectivos. Se espera que esto sirva para integrar la masividad como una variable capaz de describir tanto modos de orden de lo urbano, como regímenes relacionales específicos a ello.

\section{EL EVENTO MASIVO}

El modelo de planeamiento intercomunal aplicado en Santiago, Valparaíso y Concepción a partir de 1960 devino en formas metropolitanas hacia los años 80, luego que una breve política de liberalización del suelo urbano abriera una ventana lo suficientemente eficiente para el acaparamiento de suelo urbano por parte de privados e implosionara tanto las regulaciones existentes como las futuras (Daher, 1989, 2017; Donoso y Sabatini, 1980; Harberger, 2020; Kast, 2020; Trivelli, 1981). La segregación de las ciudades chilenas, la fragmentación de su planificación interna, la distribución desigual de infraestructuras y recursos tiene su origen en este punto, donde también lo tiene la separación entre la ciudad y sus poblaciones, sobre todo si ésta es solo expresión de un modelo de renta y no del modelo productivo para el que fue diseñada, pues no hay un hacer que involucre a quienes la habitan y los vincule al destino de las ciudades, que los articule como actor colectivo por medio de la confianza de constituirse como comunidad.

Las protestas masivas de fines de 2019 y comienzos de 2020 notifican de un momento crítico en el estado de un orden urbano que logra ser comprendido por las élites como la acción de algo con lo que no pueden parlamentar o negociar. De ello da evidencia un audio, difundido en redes sociales durante la noche del 18 de octubre, donde relata Cecilia Morel, esposa del presidente Piñera, la información que, se supone, manejaba el círculo más íntimo del gobierno:

Amiga, yo creo que lo más importante es tratar de nosotros mantener la cabeza fría, no seguir calentándonos, porque lo que viene es muy, muy, muy grave. Adelantaron el toque de queda porque se supo que la estrategia es romper toda la cadena de abastecimiento, de alimentos, incluso en algunas zonas el agua, las farmacias, intentaron quemar un hospital e intentaron tomarse el aeropuerto, o sea, estamos absolutamente sobrepasados, es como una invasión extranjera, alienígena, no sé cómo se dice, y no tenemos las herramientas para combatirlas (Leal, 2019)

No hay indicios de que lo que se señala en el audio ocurriera de verdad: ni se atacaron farmacias, ni se consignan intentos de quemar un hospital o de quemar el aeropuerto. Sin embargo, su origen permite suponer que la Presidencia y su entorno recibieron información sobre la acción de un actor poderoso y despiadado, con capacidad de quemar hospitales y el único aeropuerto internacional del país, anulando al conjunto de las Fuerzas Armadas y de Orden. Tal actor no podía ser convocado al diálogo. Morel termina el audio aconsejándole a su interlocutora en ese sentido: "Por favor, mantengamos nosotros la calma, llamemos a la gente de buena voluntad, aprovechen de racionar la comida, y vamos a tener que disminuir nuestros privilegios y compartir con los demás" (Leal, 2019).

Dos días después, la noche del domingo 20 de octubre, el presidente de la República advierte al país que "mañana será un día difícil" (Andrews, 2019) al explicar que el Ejército había tomado el control de la capital y de las ciudades internas del país con 9.500 efectivos y la Armada el control de las ciudades costeras. "Estamos muy conscientes de que tienen (los manifestantes) un grado de organización y logística que es propia de la organización criminal", sostiene, "estamos en guerra contra un enemigo poderoso, que está dispuesto a usar la violencia sin ningún límite" (Ibid.), agrega. Sin embargo, esta narrativa será desmontada al día siguiente por el mismo General Javier Iturriaga, en control de las ciudades con protestas: "Soy un hombre feliz, no estoy en guerra con nadie" (CNN Chile, 2019) sostuvo, al informar que solo se podrían abrir 18 supermercados en la capital, bajo custodia.

Paralelo a esto, el arquitecto y asesor urbano, Ivan Poduje, desplegó a los profesionales de su 
empresa el sábado 19 con el fin de hacer un catastro del daño de las protestas en la Alameda de Santiago (Atisba, 2019a) y en El Plan, en Valparaíso (Atisba, 2019b). En "Estallido Social. Eje Alameda Providencia. Impactos sociales, urbanos y económicos", presentado por Atisba un mes después, el equipo de trabajo dirigido por Iván Poduje y conformado por Eduardo Mieres, Javier Vergara y Claudio Iribarne, se articula un amplio registro de los daños en edificios y espacios públicos producidos durante el estallido en toda la extensión de la línea 1 de Metro y los caracteriza según su intensidad.

En dicho texto se equipara la evasión del pasaje de metro, que constaba en sortear masivamente los controles individuales de entrada, saltándolos, como ocurre en innumerables películas de acción y que da inicio a las acciones de desobediencia civil que desencadena el estallido, con la quema de material que obstaculiza el tráfico de superficie (barricadas), los saqueos y los destrozos de mobiliario público. El documento sostiene que "han existido grupos violentos que han generado evasiones masivas, barricadas, saqueos y destrozos aprovechando la instancia del movimiento social" (Atisba, 2019a, p. 5), y al no diferenciar actores ni acciones entre sí facilita su configuración como una sola entidad monstruosa, como plantea un año después el informe de uno de sus autores: "el monstruo que azotó a Santiago" (Poduje, 2020).

El reporte de Atisba informa sobre lo observado en un recorrido de 21 kilómetros del eje Alameda Providencia, dentro del cual se van verificando tres categorías de daños en todos los edificios de esta única calle: vandalizados, cerrados y destruidos. Lo primero indica que el edificio presenta daños en revestimientos, rayados o destrucción parcial de fachadas e incluye también aquellos que fueron blindados para evitar daños. Se entiende que esta categoría es demasiado amplia y equipara la presencia de un rayado a la destrucción parcial de fachadas, por lo que su número no puede ser masivo.

La segunda y tercera categoría son más específicas e informan de los locales cerrados y de los destruidos por ataques incendiarios. Sin embargo, entre estos últimos se considera como destruido el edificio de Enel, cuya escalera de emergencia sufrió un incendio sin que ello implicará la destrucción del edificio ni se determinará el origen del fuego (Diaz Montero, 2021). Estas imprecisiones permiten abultar las cifras, sin perjuicio de que éstas tengan un base real de daños a edificaciones y mobiliario urbano, las que se fijan en 263.297 metros cuadrados vandalizados (67\% del daño), 96.314 metros cuadrados cerrados (y vandalizados, 25\% del daño) y 31.291 metros cuadros destruidos por ataques incendiarios (18 inmuebles), cuya reparación requerirá de 106 millones de dólares calculados en diciembre de 2019 (Atisba, 2019a).

Tal ejercicio catastral, necesario en términos de exploración metodológica, es insuficiente si se considera que solo se refiere a los 21 kilómetros de una "calle recta" y no las zonas completas donde se produjeron actos vandálicos, saqueos y destrozos, ni a otras ciudades donde estos también se produjeron. De manera que en Siete Kabezas (Poduje, 2020), un texto y un sitio web donde se personifica el fenómeno como un monstruo que desola Santiago sin considerar la escala nacional de la protesta, Poduje elige una bestia de siete cabezas, tomado del libro de Apocalipsis como metáfora del enemigo señalado por Piñera. El significado simbólico de esa bestia bíblica es fértil, y por lo mismo impreciso. Se dice que se trata de siete potencias geopolíticas, siete gobiernos a los que "se le dio autoridad sobre toda tribu y pueblo y lengua y nación" (Juan 13:7), por tanto, de naturaleza humana y extranjera, como sostienen los audios de Morel.

Poduje corrobora el lenguaje de 'guerra' empleado por el presidente Piñera para acotar al tipo de actor que se enfrentaba mediante la guerra: un monstruo, pero hace poco caso a las condicionantes simbólicas de la metáfora elegida y describe, en realidad, siete problemas urbanos que afectan a Santiago en tanto colectivo urbano. El monstruo tiene un origen endógeno y ha surgido de la propia obra de quienes se aprontan a padecerlo: el colectivo de la élite política, económica e intelectual de Chile. Las cabezas del monstruo son los efectos de sus obras: la segregación urbana (cabeza uno); las demandas por infraestructura educacional y educación pública de calidad (cabeza 2); las barras de los equipos de fútbol (cabeza 3); la izquierda parlamentaria (cabeza 4); clases medias y sus aspiraciones (cabeza 5); segmentos reformistas, que identifica como "cultura caviar" (cabeza 6) y un comodín que no conocemos, pero que detonó los incendios del metro el 18 de octubre (Poduje, 2020).

Para Poduje (2020), este efecto agregado creció y se adueñó de un Santiago fracturado en dos ciudades, una ciudad de élite que goza de privilegios, amplias avenidas y parques, y otra que no tiene ninguno, solo un mal vivir heredado de políticas públicas mal diseñadas, y de la desidia de una élite que se reparte los cargos públicos en cada elección. Cada decisión segregativa habría alimentado la escala de la bestia hasta que una 
por una cada cabeza despertó y comenzó a actuar según su parecer.

La imagen es notable, pero nuevamente imprecisa. Primero porque no se trata de un fenómeno exclusivamente local. No ocurre solo en Santiago, sino en todo el país. Y no es solo el efecto del actuar displicente de un colectivo, sino el de un modelo de desarrollo socioeconómico basado en el sobre trabajo, de un planeamiento urbano basado en la segregación de servicios y calidad de viviendas, y un modelo de acumulación individual sin reintegro social, lo que fractura la solidaridad y la confianza en la sociedad chilena y en sus ciudades. El fenómeno comienza en Santiago, pero se replica en todas las ciudades metropolitanas e intermedias del país, es decir, todas las que han podido ver implementado el urbanismo neoliberal.

Esta faceta local es utilizada ya en un texto de abierta ficción, por el escritor y ex ministro de Cultura y de Relaciones Exteriores del gobierno de Piñera, Roberto Ampuero. En Demonio (2021), el embajador chileno en España retoma la narrativa de la conspiración internacional esta vez en marco donde las libertades de ficción le permiten hacerlo algo más corpóreo y real: una organización clandestina es la que detona todo, mientras el narco y el lumpen simplemente aprovechan las aguas revueltas para pescar. El desorden provocado por estos actores colectivos en la ciudad facilita el desarrollo de una guerra difícil de vislumbrar con claridad. Para enfrentar al demonio, el bien, encarnado en las élites, se debe retomar con firmeza el gobierno de la ciudad asolada por el narco, el lumpen y los terroristas, ese "enemigo poderoso e implacable" que no es uno sino muchos.

Sin embargo, en contradicción con estos enfoques, la prensa informaba sobre casos como el del concejal Chahuán, de la ciudad de La Calera, del partido del presidente de la república, Renovación Nacional (RN), primo del senador por la zona, que lideró el saqueo al centro comercial local (Cooperativa.cl, 2019). En la ciudad de Santiago, un asesor de un concejal RN de la Municipalidad de Santiago, fue despedido por organizar saqueos en la comuna peri céntrica de La Cisterna (Leal, 2019b), que no correspondían a terroristas, barras bravas o narcotraficantes, pero enuncian que la justificación de estos actos no radica en la unidad de propósito de colectivos sino también en la fatiga de la cohesión social de los actores individuales.

Por cierto, los repertorios de protesta y desobediencia del orden urbano venían desarrollándose con anterioridad en la misma capital, como ocu- rría con la paulatina ocupación habitacional de las plazas por parte de personas en situación de calle que se instalaban en ellas con sus carpas, lo que venía masificándose desde el 2016 y que llegó a su mayor punto cuando algunas personas ocuparon el bandejón central de la principal avenida de Santiago (La Alameda), en algunos casos a menos de doscientos metros de la Casa de Gobierno. A estos cabe sumar la desobediencia de las empresas constructoras e inmobiliarias a las normas urbanas que, pese a ser reconocida en tribunales, no conducía a la demolición de lo edificado contra norma, sobre todo si eran edificios residenciales en altura. De manera que los eventos de octubre de 2019 son el corolario de la fatiga en la legitimidad de un modo de orden urbano y social (capitalismo neoliberal) que las élites políticas y económicas propusieron a la sociedad chilena.

\section{LAS POLÍTICAS DE CONTENCIÓN ANTERIORES}

"El siglo XIX pesa sobre nosotros como una pesadiIla", señalaba el sociólogo Charles Tilly, "basta mirar el mapa de cualquier ciudad americana. Sus huellas están por doquier" (1991, p. 15) y ello no es diferente en cualquier ciudad occidental, sobre todo en aquellas que creyeron las promesas racionalistas de la modernidad. Sus mapas y plantas, sus grillas viales y sus barrios, reflejan las huellas de los modos como sociedades anteriores buscaron resolver racional y materialmente sus contiendas, enfrentaron sus pesadillas y organizaron en el espacio las formas que les permitían confiar en sus ciudades (Hanagan y Tilly, 2011; Tilly y Tarrow, 2015).

La confianza es un elemento clave de la contención. Si las ciudades no pueden entenderse sólo como el resultado de la agregación poblaciones humanas, ni como la mera sumatoria de edificaciones y vías que facilitan la actividad humana, es porque de la misma manera como presentan una faceta infraestructural, que facilita o dificulta actividades, también ofrecen una faceta semiótica, que nos narra el valor o significado de las acciones y prácticas dentro de este orden de relaciones que se organiza en torno a una zoología de actores conocida. Scott Lash y John Urry (1998) denominan a ello 'economías de signo y espacio', dado su carácter situado y funcional, pero John Law y Annemarie Mol $(1995,2008)$ también proponen considerarlo como 'semióticas materiales', tomando en cuenta 
los modos relacionales que movilizan a través de los arreglos materialmente expresados y las poblaciones de actores a los que apelan. Al respecto, y no por nada, para su trabajo sobre la heterogeneidad epistemológica Law y Mol utilizaron de ejemplo las diferentes semióticas que se organizaban en torno a una oveja de Cumbria, pues confiaban en que ese simple actor sería capaz de denotar el conjunto de interacciones de las que era efecto, y con ello los otros tipos de actores que estaban involucrados. Algo similar, aunque no igual, ocurre con las ciudades.

El orden espacial de las ciudades chilenas no está hecho para soportar actores masivos, pero tampoco es sordo a sus operaciones. El orden de las ciudades coloniales, por ejemplo, era una evolución del modelo de ciudad de ocupación española, las que a su vez venían de campamentos de ocupación romana (Delfante, 2005). Ese modelo de ordenamiento consideraba la existencia de un enemigo frente al cual no siempre oponía un muro, por tanto, su forma planificaba especialmente un modo de defensa que se basaba en diluir la masividad atacante en una grilla de manzanas amuralladas y vías simétricas.

Esta función de la ciudad como defensa no podía considerar grandes espacios abiertos, por lo que su única plaza considerada era la principal, la Plaza de Armas, que era el espacio público donde eran visibles los actores individuales y colectivos, y sus actos masivos. La ciudad decimonónica inicial, posterior a la independencia, no alteró la grilla colonial pero luego de la revolución de 1859, y en particular, el gobierno del Intendente liberal Benjamín Vicuña Mackenna, implementó un orden urbano diferente, que incluía plazas y avenidas públicas a la vez que segregaba a los habitantes estables y adinerados de la ciudad sólidamente construida, de aquella de los extramuros, que no entraba en los dibujos de planificación como el plano elaborado por Ansart y que levantaba sus construcciones con material desechable, ya que los suelos eran arrendados a sus ocupantes (Vyhmeister-Fábregas, 2019).

Lo anterior dio origen a extensas barriadas pobres que se ubicaron fuera de los caminos de cintura que bordeaban las grillas coloniales. Para los actos y saqueos de celebración de los vencedores de la Revolución de 1891 en Santiago y para la ocupación de Valparaíso, las poblaciones de dichas barriadas ocuparon por días los centros de esas ciudades, lo que se repitió en las protestas debido al alza del precio de la carne y los pasajes de la locomoción en 1905. Esos fueron los primeros eventos de protesta masiva que motivaron urgentes políticas de contención social, como la Ley de Habitaciones Obreras de 1906 y la consolidación de planificación urbana en el país.

Ante la falta de seguridad que ofrecían los centros urbanos, expuestos ahora por amplias vías que los cruzaban, las élites sociales abandonaron los espacios centrales en busca de periferias seguras, lo que ayudó a la implementación de modelos de planificación urbana nuclear como los de CamiIlo Sitté y los de Ebenizer Howard, que no reordenaron propiamente las ciudades, pero agregaron a ellas áreas de ordenamiento diferentes que consolidaron su segregación. De manera simultánea entre 1910 y 1950 se elaboraron diversos modelos de reordenamiento urbano basados en la integración vial mediante diagonales de los cuales el más avanzado fue el plan Brunner (Gurovich, 2003), que no lograron ser implementados antes de las protestas masivas de 1949 y 1957, provocadas ambas por el aumento del precio de pasajes de un sistema de transporte público en las ciudades de Santiago, Valparaíso y Concepción (Milos, 2007).

Solo algunos meses después de las protestas de 1957, el Estado compró la tesis sobre el Plan Regulador para Santiago de los arquitectos recién egresados Juan Honold, Pastor Correa y Jorge Martínez, la base del Plan Regulador Metropolitano (PRM60). La propuesta proponía un orden urbano adecuado al modelo de sociedad desarroIlista y reordenaba en su función las relaciones urbanas entre sus actores y colectivos. Sacaba las industrias contaminantes de los paños centrales hacia la periferia sur y abordaba las movilidades a partir de grandes avenidas estructurantes que incluían un nuevo anillo interno para la ciudad (Vespucio). Si bien el plan dividía la ciudad en diferentes unidades territoriales basadas en infraestructuras de servicios (comunas) consolidando la división de subdelegaciones utilizado por Vicuña Mackenna, al mismo tiempo integraba y distribuía los recursos urbanos, como parques, rellenos sanitarios, hospitales y vías, entre ellas, sin articular un modo de segregación socioeconómica sino una división socio funcional.

Una de las particularidades del PRM60, cuya implementación definitiva estuvo a cargo del arquitecto Juan Parrochia, fue la inclusión en éste de vías de tren subterráneo (Metro), que debían mejorar la movilidad entre comunas y que se integraba con las avenidas de ocho carriles de la superficie y que lo hicieron durante décadas, hasta que una 
nueva alza de su pasaje terminó por fatigar tanto el modelo urbano, como su gobernanza política, dando pie a las nuevas protestas masivas comenzadas en octubre de 2019.

\section{LOS REPERTORIOS DE LA ACCIÓN MASIVA}

Tal como la acción colectiva conlleva repertorios de acción tales como estrategias, tácticas y artefactos $u$ objetualidades que se movilizan en función del cumplimiento de objetivos, la acción masiva implica repertorios específicos, pero éstos no se asemejan a los anteriores pues, aún cuando también parecen orientados hacia la constitución identitaria (Negri, 2015; Tarrow, 2012), acciones estratégicas que requieren del reconocimiento del otro (Taylor, 2001) se encuentran fuera de las herramientas observadas. De esta manera, repertorios como el parlamento y la negociación, esenciales para la acción colectiva, y tanto para Leviatán como para Behemoth, son irrealizables con un actor masivo.

Un claro ejemplo de esto es que, ante la imposibilidad de convocar a los actores masivos a parlamentar y negociar el fin de las protestas, los actores colectivos escenificaron un parlamento y una negociación que, finalmente firmada por presidentes y representantes de partidos políticos, enarboló un Acuerdo Por la Paz Social y la Nueva Constitución entre actores que no participaban de la "guerra" (Partidos Políticos Chilenos, 2019). Este evidente absurdo es el efecto de la disonancia que produce este tipo de actor que no se mueve bajo las mismas reglas que los actores individuales y colectivos, y torna inútiles los repertorios de acción no por subvertirlos, sino por no corroborarlos.

Isabel Stengers (2005) toma como ejemplo de esta disonancia la historia de Bartleby, una novela corta de Herman Melville, donde este personaje testarudo solo tiene una respuesta para todo lo que se le propone: "preferiría no hacerlo" (I would prefer not to). Para Stengers, el personaje es interesante pues nunca es posible conocer el origen de su indiferencia ni comprender a cabalidad el sentido de sus acciones, si es que las tienen. Esa negación al parlamento y a la negociación ocurre también con las entidades naturales. No es posible negociar con el mar un borde costero seguro, ni con los lobos marinos la ocupación de las playas, de modo que la política del parlamento y el acuerdo (y de la democracia) no es posible de ser realizada con estos tipos de actores.

A pesar de ello, su masividad nos produce embelesamiento pues moviliza efectos estéticos difíciles de obtener para actores de escala menor. Es lo que el historiador David Nye (1994) identifica con lo sublime y que toma del debate estético del romántico europeo. En este debate, que incluye a las bellas artes y a la arquitectura, lo sublime suele ser vasto e impresionante, produciendo imágenes que, a través de contraste de luz y oscuridad, producen en quien los observa sentimientos de presentimiento, miedo y expectación. Originalmente se asocia lo sublime a la observación de la vastedad natural, pero Nye propone que ello también puede ser aplicado al efecto estético de las vastedades tecnológicas, como las enormes turbinas y murallas de una gigantesca represa o el mar de luces de una metrópolis electrificada (Nye, 1994, 2018), y a la observación de sublimes urbanos como ocurre con los rascacielos, los skylines y los conjuntos vastos de edificios en altura, o de ventanas, en las ciudades verticalizadas (Nye, 2021).

Observar un actor masivo produce el mismo efecto, pues la vastedad de su extensión lo vuelve, como en los sublimes tecnológicos, una forma de paisaje. En este caso, las protestas masivas se configuran como un actor/paisaje que no deja espacios vacíos a la vista externa. Lo sublime urbano resulta entonces una de las formas objetuales del actor masivo observado en las ciudades chilenas, pero no es su único efecto material a nivel de paisaje, pues los actores individuales y colectivos también tuvieron reacciones que evidencian la realidad de lo que enfrentaban.

Bunkering es un término inglés utilizado para describir el repostaje y abastecimiento de combustible utilizado por buques en alta mar. Los arquitectos Jeannette Plaut, Marcelo Sarovic y Marés Sandor lo utilizan para titular un libro que recoge los testimonios de 75 destacados personajes de la arquitectura, el diseño y el arte de su encierro durante la pandemia. La idea, explicaba Marés Sandor, "era que cada uno desde el aislamiento, desde el interior de sus viviendas, desde el confinamiento reflexionara sobre lo que le está pasando y que saque una foto" (Alcaíno, 2021) lo que organiza una impresión diferente de la palabra bunkering, dado que es una reflexión desde el encierro protectivo, desde el insolamiento como un repertorio de la inmunización sanitaria, sobre un tipo de operación a la que Peter Sloterdijk había dedicado ya una extensa revisión en su trilogía Esferas. 
Es esta segunda acepción de bunkering, forzada por el gesto de protección material hacia lo externo a través de gestos duros, dado que un búnker es sobre todo lo contrario a la fragilidad material, se describe bien uno de los efectos urbanos más claros de las movilizaciones comenzadas en octubre de 2019: no solo edificios y locales comerciales cerraron sus cortinas como gesto de protección, sino que con los días eso fue reforzado por cubiertas de madera, latón y acero que fueron clavadas y soldadas a las estructuras, "bunkerizando" no sólo los locales y edificios en términos singulares, sino que por agregación y contagio a los paños centrales y comerciales de las ciudades metropolitanas e intermedias.

A diferencia de las protestas urbanas anteriores, esta vez los encargados de la planificación de las ciudades no han enunciado cambios en su forma de organizar el espacio o modos de ampliación. En cambio, las edificaciones se han "bunkerizado", cerrando con placas de latón, madera o acero sus fenestraciones y entradas y haciendo del bunkering una práctica sociomaterial presente en todas las ciudades, sobre todo, pero no exclusivamente, en sus sectores y arterias comerciales.

El patrón de expansión de estas prácticas, similares a las de un contagio, ya se había observado en el cambio de las formas arquitectónicas coloniales a las neoclásicas, y luego en el cambio entre las arquitecturas de baja y mediana altura a los densos edificios de departamentos, ambos en la ciudad de Santiago, aunque separados por 150 años. El detonante puede ser el gusto, la necesidad o lucro, pero las formas arquitectónicas nuevas surgen y se contagian en radios pequeños. Colonizan, por así decirlo, una manzana, luego un otra y luego la siguiente. Las primeras casas coIoniales en desaparecer fueron las cercanas a la Alameda, una avenida peri céntrica pero transitada del Santiago decimonónico; luego vino un plan urbano y luego varios más para consolidar el cambio arquitectónico y urbano. De la misma manera, los primeros edificios residenciales densos surgieron en las avenidas periféricas de la comuna Santiago de inicios del siglo XX. Hacia la zona poniente no lograron consolidarse, pero sí lo hicieron en la zona sur, en los bordes de la Avenida Santa Isabel. Y luego vinieron los planes urbanos, nuevas densidades para las manzanas y estas formas se consolidaron.

Los eventos de protesta iniciados en octubre de 2019 trajeron consigo este nuevo repertorio de cambio urbano centrado en las cubiertas. Una arquitectura de planchas de madera aglomerada cubrió apresuradamente las vitrinas, paredes vidriadas y accesos de los locales comerciales cercanos a los lugares de manifestación. Luego, estos repertorios fueron utilizados para proteger edificios corporativos, edificios en venta, edificios de asociaciones, públicos y de bancos. Se entendió que el ejercicio inicial de protección comenzaba a consolidarse cuando la materialidad de los nuevos recubrimientos pasó de la madera al metal, y las placas fueron soldadas a las estructuras de los edificios. Incluso un banco los rediseñó según su imagen corporativa, de colores alegres y figuras abstractas como créditos.

Luego vino la expansión. Si los primeros brotes de bunkering surgieron en las cercanías de los lugares de protesta de Santiago, a una semana ya se expandían en todas las ciudades del país en protesta, y luego a los sectores y barrios lejanos a las movilizaciones. Finalmente, fueron integrados a los repertorios materiales de las instituciones con la pandemia del COVID 19 pues no solo eran útiles para mantener al manifestante fuera y proteger los locales, también lo eran para mantenerlos seguros en los largos períodos de cuarentena y para acotar el acceso en los tiempos de aforos limitados.

Luego de dos años, transitar por los centros urbanos chilenos y/o por sus calles comerciales es hacerlo por senderos de bunkering, por galerías de placas metálicas. Las ciudades se han calcificado relacionalmente y ya no abundan basureros o perros callejeros. La construcción material que produjo el estallido social parece haberse perpetuado en la pandemia, y las ciudades han visto crecer los trozos de un nuevo caparazón interno. No es nuevo, ante el temor al robo, las ciudades metropolitanas chilenas llevan décadas de proliferación de fenestraciones enrejadas y cercos perimetrales electrificados. Ahora se suma la operación cotidiana de los espacios públicos y del comercio, contagiados ya no por edificaciones de formas nuevas sino por arquitecturas de insolamiento molecular. Este cambio urbano no viene de la planificación armónica, sino del aislamiento planificado de cada actividad asociada al habitar. Consolida mediante una operación material que endurece los materiales de recubrimiento, tornándolos una estrategia de protección, ante el déficit de cohesión entre las partes moleculares de las ciudades. Recordemos que ya en 1998, solo un $17 \%$ de los chilenos creía que podía confiar en otra persona, y eso se ha mantenido así por décadas, de modo que no es extraño que ese fenómeno social se cristalice masivamente. 


\section{CONCLUSIÓN. HABLAR CON LO MASIVO}

El arquitecto Juan Honold contaba que para pasar de la tesis comprada por el Estado en 1957 al Plan Regulador Metropolitano de 1960 hubo que hacer adaptaciones. Para ello recorrió la ciudad verificando, anotando, dibujando y fotografiando qué había en los espacios donde luego se construirían avenidas y viviendas. Entendió que las casas que veía serían algún día remplazadas por otras edificaciones y que algunos terrenos, cercanos a las futuras vías demorarían décadas en ser ocupados residencialmente. Por ello calculó una densidad por manzana que condujera a que las nuevas edificaciones no fueran mayores de cuatro pisos (sin ascensor) y que amplios sectores de suelo urbano periférico pudiesen ser dedicados al comercio. Mas, para concretar eso en el PRM60, no solo debió recorrer la ciudad de extremo a extremo, tuvo que hablar con alcaldes de todos los colores políticos y con diverso nivel educativo, con agrupaciones de vecinos y de postulantes a viviendas, de propietarios y comerciantes, con ministros de diferentes gobiernos e incluso con representantes de la orden religiosa que regentaba el colegio donde él mismo había estudiado, y que sería expropiado y demolido para que la carretera interamericana (Norte/Sur) pasara por allí, descongestionando el flujo a través de la ciudad.

Dicho de otra manera, para concretizar la idea de la planificación de Santiago de 1960, sus autores no sólo debieron de ser dotados de la autoridad administrativa para llevarlo a cabo -lo cual los equipaba para actuar en una escala mayor a la escala posible para la acción individual (Vinck, 2009)- sino que tampoco pudieron renunciar a esta escala menor pues a su vez debieron parlamentar y negociar con otros actores que la planificación involucraba, escuchándolos, integrándolos y movilizándolos en función de ésta, pues tanto Honold como sus compañeros/as entendían estar articulando una forma de sociedad urbana. La narrativa moderna del progreso desarrollista, dentro de la cual la racionalización técnica y el incremento de las capacidades productivas eran argumentos que justificaban la acción individual y colectiva, servía de punto de apoyo para las conversaciones, correcciones y acuerdos. Constituía una narrativa capaz de "mover el mundo" (Callon, 1984; Latour, 1983).

La narrativa racional desarrollista acompañó tanto el ordenamiento urbano como la política de vivienda y el diseño tipológico de ésta hasta me- diados de la década de 90. A partir de ello las narrativas neoliberales lograron hacerse hegemónicas tanto en la planificación como en el diseño de viviendas y barrios (Vergara-Perucich, 2019), permitiendo la emergencia de nuevas entidades urbanas individuales y colectivas que la movilizaron.

El tipo de reflexiones del racional desarrollismo, que apelan a la articulación dialógica entre la acción individual y la acción colectiva, no acompañan a las historias de los actores masivos. Sus enunciados no son eficientes, y aunque contienen ecos de los regímenes de autoridad que convocan a los actores colectivos y de los actores individuales, no son capaces de parlamentar y negociar sus intereses con otros. Esto ha llevado a sugerir que estas entidades masivas requieren del desarrollo de otros tipos de política, que eludan el problema de la negociación sin sacrificar un marco de sentido cooperativo. Susan Leigh Star propuso la estandarización, entre otros instrumentos de fronteras como expresión de aquello (Lampland y Star, 2009), y autoras como Isabelle Stengers (2019) y Donna Haraway (2019), han propuesto otras formas políticas, especulativas, para organizar la relación con este tipo de entidades, ya sean sociales o naturales.

Las entidades masivas pueden surgir como asociaciones racionales, como ocurre con las empresas inmobiliarias, pero cuando se articulan como actores de efecto masivo, el diálogo, los acuerdos y la corroboración de las normas se torna imposible, como se ha visto en su utilización hasta el límite de la liberación de densidades de los paños de suelo de las comunas peri céntricas y periféricas; esto a su vez explica la emergencia de otros colectivos de entidades urbanas conocidos como guetos verticales, edificios residenciales en altura del alta densidad poblacional (Rojas, 2017; Vergara Vidal, 2017, 2020) y guetos urbanos (Atisba, 2010), resultado de políticas de erradicación de viviendas pobres desde el peri centro urbano hacia la periferia, donde inmobiliarias (como COPEVA, entre otros) ${ }^{1}$ articularon conjuntos masivos de vivienda de mala calidad y escasas dimensiones, entre ellos, Bajos de Mena, que tenía una den-

\footnotetext{
1. En 1996, el dueño de COPEVA, Francisco Pérez Yoma, hermano del entonces ministro de Defensa, Edmundo Pérez Yoma (DC) regaló dos caballos al ministro de Vivienda, Edmundo Hermosilla (DC), lo que desató un escándalo luego que las casas construidas por COPEVA presentaran diversas fallas de construcción (Radio Duna, 2015)
} 
sidad similar al de una ciudad intermedia chilena (Hidalgo et. al, 2016, 2017).

El marco relacional que articulan estas entidades resulta comprensiblemente polar. Por un lado, hay entidades colectivas de efecto masivo, como inmobiliarias, clase política y otras similares, que dan cuenta de las acciones urbanas de una élite de altos ingresos, con alta educación e incidencia política; y por otro, los diferentes guetos y la población masivamente excluida que no es convocada por la acción de los colectivos políticos, incluso críticos al modelo, que no aumentan sus votaciones, pero que acuden a las protestas masivas como las ocurridas en 2006, 2011, 2019 y principios de 2020.

Pero no es solo por sí misma que esta población se articula como entidad masiva. Son sus interactores los que también la identifican como tal y tratan de fijarla como una otredad monstruosa, que a la vez indica un fenómeno nuevo como algo a lo cual temer. A este enemigo/monstruo/demonio se le atribuye tanto tener unidad de propósito como no tenerlo, pero si tomamos en cuenta la distinción que hace Hobbes, las diferencias entre Leviatán y Behemoth no son útiles si sólo estamos buscando entidades colectivas, de hecho, solo considerados como conjunto alterno lo son. Es difícil señalar qué se puede esperar de la acción de las entidades masivas. En los inicios de la sociología, autores como Le Blanc, Tarde y Park ensayaron las explicaciones de lo que entonces se denominó masas, algo que el modernismo ayudó a olvidar, pero que las políticas neoliberales han traído de vuelta, al punto que es posible considerar toda una fase del capitalismo basada en este tipo de actores masivos (Sundararajan, 2016). Sin embargo, no hay que olvidar un aspecto novedoso de lo actual: las entidades masivas pueden ser también entidades naturales.

Justo cuando se podía compartir la crítica de Tilly (1991), sobre el peso del siglo pasado en nuestras ciudades, hubo que reconocer que la peste española no detuvo los fenómenos de masas de la segunda década del siglo XX, como sus revoluciones y sus guerras (Spinney, 2018). En cambio, ahora, la acción de una entidad masiva natural, COVID 19, fue capaz de aplacar al estaIlido y resignificar sus repertorios. Ello no significa que los aplacó, pues si bien las protestas se han replegado de las calles, la bunkerización ha pasado de los bancos a las viviendas, y una nueva acción de bunkerización masiva ha tomado forma a través de aforos limitados, espacios sucios, alcohol, desinfectantes y mascarillas.

La acción de las entidades masivas no debiera ser obviada del análisis urbano, sino al contrario. El pedestal vacío, rodeado por un cierre de placas de acero en la pequeña Plaza Baquedano - también llamada Plaza de la Dignidad a raíz del estallido- , las carpas de personas y colectivos en situación de calle ocupando las plazas y espacios públicos, las extensas áreas ocupadas por edificios residenciales altos y densos, y las nuevas tomas de terreno con fines habitaciones (CNN Chile, 2021) expresan parte de las semióticas materiales mediante las cuales los actores masivos dejan de ser masas efímeras para constituirse como masividades persistentes o entidades masivas.

Claramente, éstas no se limitan a las protestas o a las medidas sanitarias de la pandemia COVID-19. La estandarización del habitar, la sanitización de las ciudades, la igualdad urbana, constituyen controversias que tienen una escala y una semiótica masiva: densidad, estandarización, replicabilidad, fluidez y continuos fragmentarios, son nociones claves dentro de un lenguaje que los actores que buscan la gobernanza en las ciudades chilenas deberán aprender a hablar.

\section{REFERENCIAS}

Alcaíno, F. (2021, 3 de mayo). Jeannette Plaut sobre libro 'Bunkering': “En un tiempo dominado por la pandemia, sentimos que no se había medido el impacto desde la cultura, el espacio público, la manera de habitar y de relacionarnos". Radio Duna. https://www.duna.cl/programa/santiago-adicto/2021/05/03/jeannette-plaut-sobre-libro-bunkering-en-un-tiempo-dominado-por-la-pandemia-sentimos-que-no-se-habia-medido-el-impacto-desde-la-cultura-el-espacio-publico-la-manera-de-habitar-y-de-relaciona/

Ampuero, R. (2021). Demonio. Editorial Sudamericana. Andrews, J. P. (2019, 20 de Octubre). Presidente Piñera: "Estamos en guerra contra un enemigo poderoso". La Tercera. https://www.latercera.com/ politica/noticia/presidente-pinera-estamos-guerra-enemigo-poderoso/870658/

Aтіsвa (2010). Guetos en Chile: Una revisión de la evidencia. Atisba.

Atisba (2019a). ATISBA Monitor. Estallido Social - Eje Alameda Providencia. Atisba.

Atisba (2019b). ATISBA Monitor. Estallido Social - Ciudad de Valparaiso. Atisba.

Bauman, Z. (2007). La hermenéutica y las ciencias sociales. Nueva Visión. 
Benjamin, W. (2012). El París de Baudelaire. Eterna Cadencia Editora.

Boltanskı, L. (2016). Enigmas y complots. Una investigación sobre las investigaciones. Fondo de Cultura Económica.

Borch, C. (2012) The Politics of Crowds: An Alternative History of Sociology. Cambridge University Press. https://doi.org/10.1017/CB09780511842160

Borch, C. (2019). Imitation, contagion, suggestion: on mimesis and society. Routledge. https://doi. org/10.4324/9781351034944

Busquet, G. (2013). La sociología urbana francesa y la evolución de las políticas urbanas de los años 1960 a los años 1980 : ¿porosidades, impermeabilidades o afinidades electivas?. Empiria. Revista De metodología De Ciencias Sociales, (27), 121-136. https://doi.org/10.5944/empiria.27.2014.10865

Callon, M. (1984). Some Elements of a Sociology of Translation: Domestication of the Scallops and the Fishermen of St Brieuc Bay. The Sociological Review, 32(1_suppl), 196-233. https://doi. org/10.1111/j.1467-954X.1984.tb00113.x

Callon, M. y Latour, B. (1981). Unscrewing the Big Leviathan; or How Actors Macrostructure Reality, and How Sociologists Help Them To Do So?. En, K. Knorr y A. Cicourel (Eds.). Advances in Social Theory and Methodology (RLE Social Theory): Toward an Integration of Micro- and Macro-Sociologies (p. 277-303). Routledge and Kegan Paul.

CNN CHILE (2019, 21 de octubre). General Iturriaga: "Soy un hombre feliz, no estoy en guerra con nadie". CNN Chile. https://www.cnnchile.com/pais/ general-iturriaga-soy-un-hombre-feliz-no-estoyen-guerra-con-nadie_20191021/

CNN Chile (2021, 06 de junio). Director del Centro de Políticas Públicas UC y resultados de encuesta Casen: "Retrocedimos cerca de 5 años en pobreza". CNN Chile. https://www.cnnchile.com/programas-completos/entrevista-ignacio-irarrazaval-encuesta-casen-pobreza-retrocedimos_20210706/

Cooperativa.cl (2019, 3 de diciembre). Concejal RN Karim Chahuan lideraba banda que hizo saqueo en La Calera, según Fiscalía. Cooperativa.cl https://www. cooperativa.cl/noticias/pais/manifestaciones/ concejal-rn-karim-chahuan-lideraba-banda-que-hizo-saqueo-en-la-calera/2019-12-03/164726.html

Daher, A. (1989). Neoliberalismo urbano en Chile. Revista de Estudios Públicos, (43), 281-299. https:// www.cepchile.cl/cep/site/artic/20160303/ asocfile/20160303184631/rev43_daher.pdf

Daher, A. (2017). En las costas del neoliberalismo. Naturaleza, urbanización y producción inmobilia- ria: experiencias en Chile y Argentina. Revista de geografía Norte Grande, (66), 211-217. https:// doi.org/10.4067/S0718-34022017000100012

De la Cadena, M (2015). Earth beings: ecologies of practice across Andean worlds. Duke University Press. https://doi.org/10.2307/j.ctv11smtkx

Delfante, C. (2006) Gran Historia de la Ciudad. De Mesopotamia a Estados Unidos. Abada Editores.

Díaz Montero, F. (2021, 18 de enero). Sin detenidos ni formalizados: a 15 meses de incendio en Enel Fiscalía aún no encuentra responsables. Biobío. https:// www.biobiochile.cl/noticias/nacional/region-metropolitana/2021/01/18/sin-detenidos-ni-formalizados-a-15-meses-de-incendio-en-enel-fiscalia-aun-no-encuentra-responsables.shtml

Donoso, F. y Sabatinı, F. (1980). Santiago: empresa inmobiliaria compra terrenos. Revista EURE - Revista de Estudios Urbano Regionales, 7(20), 2552. http://www.eure.cl/index.php/eure/article/ view/900

DurkheIm, E. (2004). El Suicidio. Losada.

Geht, J. (2010). Cities for People. Island Press.

GuRovich, A. (2003). La solitaria estrella: en torno a la realización del Barrio Cívico de Santiago de Chile, 1846-1946. Revista de Urbanismo, (7), 1-28. https://revistaurbanismo.uchile.cl/index.php/ $\mathrm{RU} /$ article/view/6214

HalbWaChS, M. (2008). Morfología social de la ciudad. En E. Martínez Gutiérrez (Ed.). Maurice Halbwachs. Estudios de morfología social de la ciudad ( $p$. 50-129). Centro de Investigaciones Sociológicas.

Hanagan, M. y Tilly C. (2011). Contention and Trust in Cities and States. Springer. https://doi.org/10.1007/97894-007-0756-6

HaRAWAY, D. (1991). Simians, cyborgs, and women: The re-invention of nature. Free Association Books.

HaRAWAY, D. (2019). Seguir con el problema: Generar parentesco en el Chthuluceno. Consonni

Harberger, A. (2020). Notas sobre los problemas de vivienda y planificación de la ciudad. Auca: Arquitectura Urbanismo Construcción Arte, (37), 39-41. https://revistadesociologia.uchile.cl/index.php/ AUCA/article/view/59685/63132

Harvey, D. (2006). París, Capital de la Modernidad. Akal Hidalgo, R., Paulsen, A. y Santana, L. (2016). El neoliberalismo subsidiario y la búsqueda de justicia e igualdad en el acceso a la vivienda social: el caso de Santiago de Chile (1970-2015). Andamios, 13(32), 57-81. https://doi.org/10.29092/uacm. v13i32.525

Hidalgo, R., Urbina, P., Alvarado, V. y Paulsen, A. (2017). Desplazados y ¿olvidados?: contradicciones respecto de la satisfacción residencial en Bajos de 
Mena, Puente Alto, Santiago de Chile. Revista INVI, 32(89), 85-110. https://doi.org/10.4067/ S0718-83582017000100085

Hoвbes, T. (1992) Behemoth. Editorial Técnos

HobBes, T. (2017). Leviatán, o la materia, forma y poder de una república eclesiástica y civil. Fondo de Cultura Económica.

KAst, M. (2020). El uso del suelo por las ciudades. Auca: Arquitectura Urbanismo Construcción Arte, (37), 38-39. https://revistas.uchile.cl/index.php/AUCA/article/view/59684/63131

LAMPLAND, M., y Star, S. L. (2009). Standards and Their Stories: How Quantifying, Classifying, and Formalizing Practices Shape Everyday Life. Cornell University Press

LASH, S. y Urry, J. (1998), Economías de signos y espacios. Sobre el capitalismo de la posorganización. Amortorrou

LATOUR, B. (1983). Give Me a Laboratory and I will Raise the World. En K. Knorr-Cetina y M. Mulkay (Eds.), Science Observed: Perspectives on the Social Study of Science (p. 141-170). Sage.

Law, J. (2008). Actor Network Theory and Material Semiotics. In The New Blackwell Companion to Social Theory. En B.S. Turner (Ed.). https://doi. org/10.1002/9781444304992.ch7

Law, J., y MoL, A. (1995). Notes on Materiality and Sociality. The Sociological Review, 43(2), 274-294. https://doi.org/10.1111/j.1467-954X.1995. tb00604.x

Le Bon, G. (2000). Psicología de las masas. Ediciones Morata.

Leal, C. (2019, 21 de octubre). Filtran audio de Cecilia Morel: tendremos que reducir nuestros privilegios y compartir con los demás. Biobío Chile. https://www.biobiochile.cl/noticias/nacional/chile/2019/10/21/filtran-audio-de-cecilia-morel-tendremos-que-reducir-nuestros-privilegios-y-compartir-con-los-demas.shtml

LeaL, C. (2019b, 30 de noviembre). Municipalidad Santiago confirma que asesor de concejal estuvo involucrado en saqueo en La Cisterna. Biobío. https://www.biobiochile.cl/noticias/nacional/ region-metropolitana/2019/11/30/municipalidad-santiago-confirma-que-asesor-de-concejal-estuvo-involucrado-en-saqueo-en-la-cisterna.shtml

Marx, K. (2007). Elementos Fundamentales para la Critica de la Economia Politica. Borrador 18571858. Volumen 1. Siglo XXI Editores.

MıLos, P. (2007). 2 de abril de 1957. Historia y Memoria. LOM.

Negri, A. (2015). El poder constituyente. Ensayo sobre las alternativas de la Modernidad. Trafican- tes de Sueños.

Negri, A. (2020). De la fábrica a la Metrópolis. Ensayos 2. Editorial Cactus.

NrQ, D. (1994). American Technological Sublime. The MIT Press.

NrQ, D. (2018). American illuminations: urban lighting, 1800-1920. The MIT Press.

NyQ, D. (2021). Conflicted American Landscapes. The MIT Press.

PARK, R. E. (1996) La masa y el público. Una investigación metodológica y sociológica. Revista Española de Investigaciones Sociológicas, (74), 361423. https://doi.org/10.2307/40183899

Partidos Políticos Chilenos (2019). Acuerdo Por la Paz Social y la Nueva Constitución. 15 de noviembre de 2019.

PelLicer, I., Rojas, J., y Vivas, P. (2014). La deriva: una técnica de investigación psicosocial acorde con la ciudad contemporánea. Boletín De Antropología, 27(44), 144-163. https://revistas.udea.edu. co/index.php/boletin/article/view/20827

Poduje, I. (2020). Siete Kabezas. Crónica urbana del estallido social. Uqbar Editores.

Radio Duna (2015, 10 de junio) Caso Copeva: A 18 años del escándalo damnificados reciben viviendas definitivas. Radio Duna. https://www. duna.cl/noticias/2015/06/10/caso-copeva-a-18-anos-del-escandalo-damnificados-reciben-viviendas-definitivas/

RoJAs, L. (2017). Ciudad Vertical: la "nueva forma" de la precariedad habitacional. Comuna de Estación Central, Santiago de Chile. Revista 180, (39).

Sevtsuk, A. (2020). Street Commerce: Creating Vibrant Urban Sidewalks (The City in the Twenty-First Century). University of Pennsylvania Press. https:// doi.org/10.9783/9780812297089

Simmel, G. (2013). Roma, Florencia, Venecia. Gedisa.

SPINNEY, L. (2020). El jinete pálido. 1918: La epidemia que cambió el mundo. Crítica

STAR, S. L. (1990). Power, Technology and the Phenomenology of Conventions: On being Allergic to Onions. The Sociological Review, 38(1_suppl), 26-56. https://doi.org/10.1111/j.1467-954X.1990. tb03347.x

Stengers, I. (2005). The cosmopolitical proposal. En B. Latour y Peter Weibel (Eds.). Making Things Public (p. 994-1003). The MIT Press.

Stenges, I. (2019). Cómo pensar juntos. Dos conferencias sobre ciencia, política y desastre. Editorial Sapostcat

Sundararajan, A. (2016). The Sharing Economy: The End of Employment and the Rise of Crowd-Based Capitalism. The MIT Press 
TARDE, G. (2011). Las Leyes de la Imitación y la Sociología. Centro de Investigaciones Sociológicas.

TARRow, S. (2012). Strangers at the gates: movements and states in contentious politics. Cambridge University Press. https://doi.org/10.1017/ CB09780511920967

TAYLOR, C. (2001). El multiculturalismo y "la política del reconocimiento". Fondo de Cultura Económica de España.

Thomas, W. I. (1923). The Unadjusted Girl with cases and standpoint for behavior analysis. Little, Brown and Company

TILLy, C. (1991). Grandes estructuras, procesos amplios, comparaciones enormes. Alianza Editorial.

Tiııy, C. y Tarrow, S. (2015). Contentious politics. Second revised edition. Oxford University Press.

TRIVELLI, P. (1981). Reflexiones en torno a la política nacional de desarrollo urbano. Revista EURE - Revista de Estudios Urbano Regionales, 8(22), 43-64.

URETA, S. (2017). Transantiago o el fallido ensamblaje de una sociedad de clase mundial. Ediciones Universidad Alberto Hurtado

Vergara, F. (2019). Urban Design under Neoliberalism: Theorising from Santiago, Chile. Routledge.

Vergara, J. (2017). Verticalización. La edificación en altura en la Región Metropolitana de Santiago (1990-2014). Revista INVI 32(90), 9-49. https:// doi.org/10.4067/S0718-83582017000200009

VERGARA VIDAL, J. (2020). La verticalización como régimen urbano. El caso de las ciudades chilenas. Cuadernos de Vivienda y Urbanismo, 13. https:// doi.org/10.11144/Javeriana.cvu13.vruc

Villarroel, M. J. (2019, 19 de octubre). 20 estaciones quemadas y 41 con diversos daños: el recuento de Metro por jornadas de protestas. Biobio Chile. https://www.biobiochile.cl/noticias/nacional/ region-metropolitana/2019/10/19/20-estaciones-quemadas-y-41-con-diversos-danos-el-recuento-de-metro-por-jornadas-de-protestas.shtml

VINCK, D. (2009). De l'objet intermédiaire à l'objet-frontière: Vers la prise en compte du travail d'équipement. Revue d'anthropologie des connaissances, 3(1), 51-72. https://doi.org/10.3917/ rac.006.0051

VyHMEISTER-FábREGAS, K. (2019). La transformación de Santiago: un caso frustrado de intervención urbana a gran escala (1872-1929). Revista EURE Revista de Estudios Urbano Regionales, 45(134), 213-235. https://doi.org/10.4067/S025071612019000100213

WalkER, S. (2009). Gordon Matta-Clark: Art, Architecture and the Attack on Modernism. I. B. Tauris. https://doi.org/10.5040/9780755697496 